\title{
Effect of pH on the compressive strength of Grey Mineral Trioxide Aggregate and Biodentine
}

\author{
Bernice Thomas ${ }^{1}$, Manoj Chandak ${ }^{2}$, Aditya Patidar ${ }^{3}$, Harshit Kothari ${ }^{4}$ \\ ${ }^{I}$ Post Graduate, Department of Conservative Dentistry and Endodontics, SharadPawar Dental College, \\ Sawangi(M), Wardha \\ ${ }^{2}$ H.O.D, Department of Conservative Dentistry and Endodontics, SharadPawar Dental College, Sawangi(M), \\ Wardha \\ ${ }^{3}$ Post Graduate, Department of Conservative Dentistry and Endodontics, SharadPawarDental College, \\ Sawangi(M), Wardha \\ ${ }^{4}$ Lectrer, Department of Conservative Dentistry and Endodontics, SharadPawar Dental College, Sawangi(M),
} Wardha

\begin{abstract}
:
Aim: The aim of this study was to compare the effect of an acidic and alkaline environment on the compressive strength of Grey Pro Root Mineral Trioxide Aggregate and Biodentine.

Methodology: A total of eightyhuman, mandibular molars were used. Perforations were made in the furcation of each molar and enlarged to \#3 Pesso drills. The repair was performed, according to the materials used. Samples of each material were repaired according to the repair material and randomly divided into two groups $(n=40), G M T A$ and Biodentine, respectively. These were further apportioned into four subgroups $(n=10)$ according to storage media and time. Four subgroups of ten samples eachwere exposed to $\mathrm{pH} 5.4$ and $\mathrm{pH} 7.4$ for 4 days respectively. Compressive strength was measured for each of the sample and was measured 4 days after the exposure.

Results: Data was subjected to one-way ANOVA using Tukey'spost hoc test. Biodentine displayed greater resistance to dislodgement than Grey Mineral Trioxide Aggregate at acidic environment, 4.66 $\pm 0.94 \mathrm{MPa}$ and $2.41 \pm 0.95$. A p-value $<0.05$ was consideredto be statistically significant.

Conclusion:In an acidic environment, compressive strength of Grey Mineral Trioxide Aggregate was affected than that of Biodentine.
\end{abstract}

Keywords:acidic, Biodentine, compressive strength, Grey Mineral Trioxide Aggregate,

\section{Introduction}

Root canal perforation accounts for the second most common cause of endodontic failure, accounting for $9.6 \%$ of all unsuccessful cases ${ }^{1}$.Farzaneh $\mathrm{M}$ et al (2004) reported that retreatment success declined from a high $89 \%$ to $42 \%$ in the presence of a preoperative perforation, despite the presence of a periradicular lesion ${ }^{2}$. Perforation can occur for a number of different reasons including aberrant canal anatomy (extra canals, excessive curvature, or calcification), misguided access preparation, and overzealous instrumentation. Studies have shown that the prognosis for cervical root and chamber floor perforation is worse than other areas of the tooth because of gingival sulcus proximity ${ }^{3,4}$. Furcal perforation can lead to periradicular breakdown eventually causing loss of gingival attachment and bone, which in many cases is not reparable $e^{4,5}$.

The prognosis for repair is usually better when the perforation is closed immediately because of increased inflammation with time $e^{4}$. An intracanal approach is preferred, potentially eliminating the need for a surgical approach or intentional replantation ${ }^{6}$.

Mineral trioxide aggregate has been used for repair of root perforations, root end filling material, vital pulp therapy including direct pulp capping and pulpotomy of immature teeth with vital pulps (apexogenesis) and as an apical barrier for teeth with open apices ${ }^{7-10}$ making it an extremely popular endodontic material. But the quench for better endodontic materials has lead to the introduction of a tricalcium silicate based material called Biodentine, which has clinical applications similar to those of MTA ${ }^{11}$. Variations in the periapical pH can affect the physical and chemical properties of a root end filling material. The effect of acidic $\mathrm{pH}$ on the compressive strength of MTA has been well studied and documented ${ }^{12}$. As sufficient literature on Biodentine is lacking, the present study was designed to evaluate the surface microhardness of the material when exposed to different levels of acidic $\mathrm{pH}$. 


\section{Materials And Methods}

\subsection{Selection of Teeth and Specimen Preparation}

Eighty human mandibular, first molars were with completely formed roots, minimal or no caries, no cracks, and no fused roots were included in the study. The selection was based on the degree of separation of the roots so as the furcal area is visible enough. Immediately after extraction the roots of each tooth was cleaned of soft tissues or bone remnants with periodontal curettes, disinfected with Sodium hypochlorite $(\mathrm{NaOCl}) 3 \%$ (Vishal) for 10 minutes and stored in normal saline solution until usage. The teeth were stored in normal saline to prevent desiccation of the teeth due to loss of moisture. Molars were amputated $3 \mathrm{~mm}$ apical to the furcation at a direction perpendicular to the long axis of the tooth using a water-cooled, diamond disc (Brasseler Dental Products, Savannah, USA). Similarly the crowns were also shortened to a level $3 \mathrm{~mm}$ coronal to the cement enamel junction using the water-cooled, diamond disc (Brasseler Dental Products, Savannah, USA). Endodontic access cavity was made in each molar, using a \#4 diamond round bur (SS White, Germany), and safe-end bur (Mani, India).

Perforations were initially created using size 1/2-round bur on a long neck (LN Bur; Maillefer, Dentsply, Switzerland) between the canal orifices in an apical direction down to the external surface of the tooth at the furcation area. The perforation was then enlarged using Pesso drills (Mani, Tochigi-ken, Japan) from size 1 to 3 , corresponding to diameter of $1.1 \mathrm{~mm}$, in a direction parallel to the long axis of the tooth.

The specimens were randomly divided into 2 equal groups according to the repair material, consisting of forty teeth each $(n=40)$ : Grey Pro Root MTA and BD. The specimens in each group were further randomly divided into 4 equal subgroups, consisting of ten teeth each $(n=10)$ according to the storage media and time to which the repair materials were exposed as follows: subgroup A: specimens were placed for 4 days in contact with PBS at $\mathrm{pH}$ of 7.4, subgroup B: specimens were placed for 4 days in contact with an acidic acetic acid solution buffered to $\mathrm{pH}$ of 5.4. The specimens were inserted in PBS-moistened floral foam to simulate as much as possible clinical conditions. The repair procedure was performed under $14 \mathrm{x}$ magnification using surgical microscope (Opmi-Pico; Karl Zeiss, Jena, Germany). The materials were mixed according to the manufacturers' instructions. They were applied into the perforation in increments using the micro apical placement system (MAP; ProduitsDentaires SA, Vevey, Switzerland) and condensed using endodontic pluggers. A cotton pellet soaked with the assigned solution for each subgroup was placed in the pulp chamber over the repair material, and the specimens were inserted in the floral foam moistened with the same respective solution. The specimens were stored at $37^{\circ} \mathrm{C}$ and $100 \%$ relative humidity. The soaked cotton was changed every 4 days.

\subsection{Assessment of Dislodgment Resistance}

The repair materials were dislodged from perforations using a universal testing machine, Instron (Model LRX-Plus; Lloyd Instruments Ltd, Fareham, UK). The repair materials were loaded using a 1-mmdiameter, cylindrical plunger to displace it in an apical-coronal direction at a load cell of $5 \mathrm{kN}$ and a crosshead speed of $0.5 \mathrm{~mm} / \mathrm{min}$ until failure.

The maximal force applied to the material before dislodgment was recorded in Newton $(\mathrm{N})$. The calculation of the push-out bond strength (MPa), as an indicator for dislodgment resistance, was done using the following equation:

Push-out bond strength $(\mathrm{MPa})=$ force to dislodgement $(\mathrm{N}) /$ adhesive surface area $(\mathrm{mm} 2)$.

Adhesive surface area $(\mathrm{mm} 2)=2 \pi \mathrm{rh}$,

Where, " $r$ " is the radius of the perforation cross-section, and

" $\mathrm{h}$ " is the height of the perforation.

\section{Results And Discussion}

After 4 days there was a statistically significant difference among groups ( $p$ value)where Biodentine had significantly highest bond strength

Dislodgment Resistance of calcium silicate based materials in various clinical situations.

TABLE: Mean push out bond strength of GMTA and Biodentine in acidic and alkaline environment.

\begin{tabular}{|c|c|c|c|c|}
\hline \multirow[t]{2}{*}{ Materials } & \multicolumn{2}{|c|}{$\begin{array}{l}\text { Specimens placed for } 4 \text { days in contact } \\
\text { with PBS at pH of } 7.4\end{array}$} & \multicolumn{2}{|c|}{$\begin{array}{l}\text { Specimens placed for } 4 \text { days in } \\
\text { contact with an acetic acid } \\
\text { solution buffered to } \mathrm{pH} \text { of } 5.4\end{array}$} \\
\hline & MEAN & SD & MEAN & SD \\
\hline Pro Root GMTA & 5.06 & 0.60 & 2.41 & 0.95 \\
\hline Biodentine & 8.62 & 2.25 & 4.66 & 0.94 \\
\hline
\end{tabular}


TABLE: Multiple comparison Tukey test for 4 days in PBS at pH 7.4.

Mean push out bond strength of GMTA was $5.06 \mathrm{MPa}$, for Biodentine it was $8.62 \mathrm{MPa}$.

On comparing push out bond strength in two groups, statistically significant difference was found between GMTA and Biodentine $(\mathrm{p}=0.009)$.

\begin{tabular}{|c|c|c|c|c|c|c|}
\hline \multirow[b]{2}{*}{ Group } & & \multirow{2}{*}{$\begin{array}{l}\text { Mean } \\
\text { Difference } \\
\text { (I-J) }\end{array}$} & \multirow{2}{*}{ Std. Error } & \multirow{2}{*}{ p-value } & \multicolumn{2}{|c|}{ 95\% Confidence Interval } \\
\hline & & & & & Lower Bound & Upper Bound \\
\hline $\mathrm{BD}$ & G-MTA & 3.55 & 0.98 & $\begin{array}{l}0.009 \\
S, p<0.05\end{array}$ & 0.93 & 6.17 \\
\hline
\end{tabular}

TABLE:Multiple comparison Tukey test for 4 days in acetic acid at $\mathrm{pH} 5.4$.

Mean push out bond strength of GMTA was $2.41 \mathrm{MPa}$, for Biodentine it was $4.66 \mathrm{MPa}$.

On comparing push out bond strength in two groups, statistically significant difference was found between GMTA and Biodentine $(\mathrm{p}=0.16)$

\begin{tabular}{|l|l|l|l|l|l|l|}
\hline \multirow{2}{*}{ Group } & & $\begin{array}{l}\text { Mean } \\
\text { Difference } \\
\text { (I-J) }\end{array}$ & Std. Error & \multirow{2}{*}{ p-value } & \multicolumn{2}{|l|}{$\mathbf{9 5 \% \text { Confidence Interval }}$} \\
\cline { 3 - 7 } & & & & Lower Bound & $\begin{array}{l}\text { Upper } \\
\text { Bound }\end{array}$ \\
\hline BD & GMTA & 2.25 & 0.67 & $0.016, \mathrm{~S}, \mathrm{p}<0.05$ & 0.44 & 4.06 \\
\hline
\end{tabular}

\section{Discussion}

A perforation repair material is invariably placed in an environment where inflammation is present and where the $\mathrm{pH}$ is likely to be acidic ${ }^{12,13}$. This acidic $\mathrm{pH}$ is likely to be an impediment to the setting reaction of Biodentine causing it to affect the compressive strengthof the set material.

Namazikhahet $\mathrm{al}^{14}$ stated that at an alkaline $\mathrm{pH}$ of7.4 the Vickers microhardness of MTA was 53.19 whichreduced radically as the $\mathrm{pH}$ was lowered.

Storm B et al ${ }^{15}$ compared the hygroscopic linearsetting expansions of GMTA, WMTA, and PC with a new device. He reported that GMTAexpanded significantly more than WMTA in either wateror HBSS immersion.GMTA had a decrease inexpansion that nearly reached significance. The small sample size may have reduced the ability to confirm this difference. HBSS containssodium hydrogen phosphate $\left(\mathrm{HNA}_{2} \mathrm{O}_{4} \mathrm{P}\right)$. Phosphate buffering couldpossibly affect setting expansion or the iron-containing componentcould have been more or less reactive in a phosphate environment. The higher level oftetracalcium aluminoferrite in GMTAreacts differentlyin HBSS than in water, it probably explaining the reduction in expansionobserved only in GMTA.

The present study was designed to compare the compressive strength of Biodentine with Grey Mineral Trioxide Aggregate (GMTA). The mean compressive strength of Biodentine in alkaline environment was $8.62 \pm 2.25 \mathrm{MPa}$, whereas in acidic environment its compressive strength was $4.66 \pm 0.94 \mathrm{MPa}$; whereas, the mean compressive strength of Grey Mineral Trioxide Aggregate (GMTA) in alkaline environment was $5.06 \pm 0.60 \mathrm{MPa}$ and in acidic environment was $2.41 \pm 0.95 \mathrm{MPa}$.

The above results indicate; that the compressive strength of a calcium silicate based materialreduced from alkaline environment to acidic environment indicating that an acidic environment alters the physicochemical properties.

Biodentine, significantly $(\mathrm{p}<0.05)$ shows higher values of compressive strength in acidic as well as in alkaline environment in comparison with GMTA.

Poplai et al also stated that surfacehardness of Biodentine was impaired in the presence of acidicenvironment ${ }^{16}$.

Higher values of microhardness of Biodentine can beexplained on the basis of calcium chloride present in the liquid provided by the manufacturer. The addition of $\mathrm{CaCl}_{2}$ is intended to reduce the setting time of the Portland cementand to improve its physicochemical properties in civilconstruction ${ }^{16}$.

\section{References:}

[1]. Ingle JI. A standard endodontic technique utilizing newly designed instruments andfilling materials. Oral Surg Oral Med Oral Pathol 1961;14:83-91.

[2]. Farzaneh M, Abitbol S, Friedman S. Treatment outcome in endodontics: the Torontostudy. Phases I and II: Orthograde retreatment. J Endod 2004;30:627-33.

[3]. Jew RCK, Weine FS, Keene JJ, Smulson MH. A histologic evaluation of periodontaltissues adjacent to root perforations filled with Cavit. Oral Surg Oral Med Oral Pathol1982;54:124 -35.

[4]. Seltzer S, Sinai I, August D. Periodontal effects of root perforations before and duringendodontic procedures. J Dent Res 1970;49:332-9. 
[5]. Meister F, Lommel J, Gerstein H, Davies EE. Endodontic perforations which resulted in alveolar bone loss. Oral Surg Oral Med Oral Pathol 1979;47:463-70.

[6]. Harris WE. A simplified method of treatment for endodontic perforations. J Endod1976;2:126 -34

[7]. Lee SJ, Monsef M, Torabinejad M. Sealing ability of a mineral trioxide aggregate for repair of lateral root perforations. J Endod 1993;19:541-44.

[8]. Torabinejad M, Watson TF, Pitt Ford TR. Sealing ability of a mineral trioxide aggregate when used as a root-end filling material. J Endod 1993;19:591-95.

[9]. Torabinejad M, Chivian N. Clinical applications of mineral trioxide aggregate. J Endod 1999;25:197-205.

[10]. Shabahag S, Torabinejad M. Treatment of teeth with open apices using mineral trioxide aggregate. PractPedodontics and Aesthet Dent 2000; 12: 315-20.

[11]. Septodont RD. Department BiodentineTM-Active Biosilicate Technology Scientific File, 2009.

[12]. Malmed SF. Handbook of local anaesthesia (5th ed). St Louis Mosby: Elsevier 2004:43-44.

[13]. Nekoofar MH, Namazikhah MS, Sheykhrezae MS, et al. pH of pus collected from periapical abscesses. IntEndod J 2009;42:534-38

[14]. Namazikhah MS, Nekoofar MH, Sheykhrezae MS, et al. The effect of $\mathrm{pH}$ on surface hardness and microstructure of mineral trioxide aggregate.IntEndod J 2008;41:108-16.

[15]. Storm B, Eichmiller FC, Tordik PA, GoodellGG.Setting expansion of gray and white mineral trioxide aggregate and Portland cement.JEndod. 2008 Jan;34(1):80-2.

[16]. Poplai G, Jadhav SK, Hegde V. Effect of Acidic Environment on the Surface Microhardness of BiodentineWorld J Dent 2013;4(2):100-102. 